windows at the back of the child that air may rush in and chill the little frame already weakened by bad air and too close application to its books. Then, as it grows older, especially if it be a girl, say 13 years of age, let the next two years be spent in the development of the body rather than forcing the mental training, as at this age the system needs all the nervous force and vital energy to establigh the normal functions of the body. We should also place our public schools under the care of intelligent and careful men and women who are competent to care for the body and mind.

\section{BROMOFORM IN PERTUSSIS.}

Read in the Section on Diseases of Children, at the Forty-sixth Annual Meting of the American Medical Association, at

BY P. J. EATON, A.M., M.D. (HARV.) PITTSBCRG, PA.

I wish to bring to your attention the results of some studies I have recently made upon bromoform; its chemistry, pharmacology, and therapeutic action in certain diseases.

Bromoform is a colorless liquid of sp. gr. 2.83 at 0 degrees $\mathrm{C}$., and is represented by the symbol $\mathrm{CH}$ $\mathrm{Br} .3$. It is produced by the action of bromin upon alcohol in the presence of an alkali. In practice, milk of lime is saturated with bromin, alcohol is added, and the mixture distilled. The resulting liquid is colorless, sweet to the taste, and gives the sensation of burning. Its physiology may be summed up in saying that it is an agreeable anesthetic, without danger, merely lowering blood pressure; a narcotic when used hypodermically; and, finally, is an antipyretic. The excitability of the psychomotor centers and the general refiexes are entirely abolished when anesthesia is complete. The urine contains bromin some hours later.

In leading up to the discussion of the value of bromoform in pertussis and certain other forms of spasmodic cough, and in referring to the methods of administration, and manner of its exhibition, I shall report briefly some cases in which the drug was used, and from these cases hope to deduce some points of interest:

Cases 1 and 2.-Father and son. Middle-aged, and $t$ years old respectively. Came to me Nov. 12, 1893, with the history of having had whooping cough since spring. They had tried many doctors and much medicine with no benefit. Both pale, and pretty well worn out. Gave bromoform in appropriate doses, and in ten days patients both reported themselves well.

Case 3.-Boy fifteen months of age. Began to whoop July 25,1894 . Had not been very well for some time, having had some intestinal indigestion. Began bromoform at once, drops 2 to 3 , four times a day. On the third day he was stupid, temperature 101.3 degrees, anorexia-malaise. Reduced the dose of bromoform for a day or two to 1 drop, occasionally omitting a dose. Then increased it, as cough was rapidly growing worse. He then took 6 drops without any bad symptoms. By the middle of August he had stopped whooping, and on August 29 , I have record of very rapid improvement. He has had one bad cold since, during which he whooped a few times. He is now, Nov. 26, 1894, in robust health.

Case 4.-Spring of 1894 ; boy 3 years of age. Mild case Bromoform given early. In seven or eight days ceased whooping. Coughed some time longer. During the summer he had one or two colds, and would give a mild whoop occasionally. General health suffered very little.

Cens's 5 and 6.-Brother and sister, 8 and 10 years of age ; summer of 1894 ; both took bromoform well, the boy recovering in ten days; the girl in two weeks. The boy bad a light attack; the girl a pretty severe one. Both had whooped a week before having any treatment.
Case 7.-Middle-aged gentleman; summer of 1894 . He had had pertussis when a child. He is father of Cases 8 and 9. Took rapidly increasing doses up to 30 drops with relief, but not complete cure. He was very much racked by the paroxysms. A sea trip from Boston to Baltimore, and continuance of the drug cured him within a week. Coughed in all, three weeks.

Cases 8 and 9.-Four-year-old girl and 1-year-old baby. Bad cases. The older child would not take the medicine well and was only relieved. The baby was taken to sea, and greatly benefited. Bromoform was not pushed to physiologic limits in either case.

Case 10.-Summer of 1893; girl 4 years of age. Mother would not give medicine regularly, and child did not improve. She coughed all summer.

Case 11.-1892; boy 3 years old. He whooped for a week or two before beginning treatment. Was seen twice at intervals of three days. Marked improvement. One day at about 1. P.M., his mother discovered the bottle of bromoform which had contained $1 \mathrm{drachm}$, about half empty. The boy denied having taken any. He was brought to my office about $2: 15$ P.M. I could smell no bromoform in his breath, and he was as bright as usual. About 6 P.M. T was summoned by telephone and found on my arrival, that the boy in running to meet his father about $5: 50$ P.M., had suddenly grown very sleepy and stupid, and soon had become comatose. Hypodermics of ether and whisky and hot enemata were given for flagging pulse. Friction to cold extremities was used, and pricking and slapping to keep patient awake. In an hour he was out of danger. Slept heavily during the night, and the following day $\mathrm{k}$ as as well as usual. No more bromoform was given, but the attack passed away very soon.

Case 12.-Summer of 1893 ; boy 8 years old. Had been whooping hard for three weeks and was pretty well used up. Made out a schedule for a week's treatment. I did not see the boy again. but met his mother on the street ten days afterward. She said she had not brought the boy to the office as requested, because he had ceased whooping at the end of five days, and was perfectly well at the time of our interview.

Case 13.-1893; girl about 5 years of age. Gave bromoform in increasing doses up to 17 drops with relief, but no very marked or prompt cure. I did not dare to give any larger doses. The attack lasted about four weeks. A sister two years older was greatly benefited by the drug, and was well long before Case 13 . Her maximum was 11 drops. Both children were singularly quiet and deliberate in their actions and very phlegmatic.

Case 14.- June 3, 1894; male, eighteen months of age. Coughed for several days. Dose, 2 up to 4 drops. A mild attack. Well in a few days.

Case 15-June 3, 1894; female 3 years of age. Coughed for several days. Dose, 3 up to 6 drops. Moderate attack. Began to diminish dose June 17,1894 . Was well in two weeks. Case 16 -. Iune 12,1894 ; female 25 years of age. Was sick several weeks. Dose, 6 up to 18 drops. Stopped whooping on June 22 . Slowly diminished the medicine.

Case 17.-June 12, 1894; female 2 years of age. Was sick several weeks. Dose, 2 up to 4 drops. Moderate attack. On $23 \mathrm{~d}$ was well of cough.

Caxe 18.-Dec. 11,1893; female sixteen months old. Was sick two weeks. Dose, 2 up to 4 drops. Mild attack. On December 23 was well.

Case 19.- Sept. 6,1893 ; female 26 years of age. Coughed for a week or two. Dose, 6 up to 20 drops. Very severe attack. By 16th much better; on 19 th only one whoop. Then diminished bromoform.

Case 20.-Sept. 6, 1893; male 3 years of age. Coughed for a week or two. Dose, 3 up to 6 drops. A moderate attack. Was well in ten days, except little loose cough.

Case 21.-Spring of 1894 ; male 8 years of age. Had cough and cold for a few days. Dose, 4 up to 9 drops. Had rather severe attack. Was well in three weeks.

Case 22.-Spring of 1894 ; female 5 years of age. Had cough and cold for a few days. Dose, 3 up to 7 drops. Mild attack. Was well in two weeks.

Case 23.-Spring of 1894 ; female 6 years old. Onset rather abrupt. Dose, 4 up to 7 drops. Mild attack. Was well in ten days.

Case 24.--Spring of 1894 ; female 3 years of age. Had catarrhal cold for a week. Dose, 3 up to 5 drops. Mild attack. Was well in twelve days.

Case 25 .- November, 1894 ; female 6 years of age. Whooped three weeks before treatment. Dose, 4 up to 9 drops. Severe attack. Well in two weeks.

Case 26. - November, 1894; female 4 years of age. Had 
whooped three weeks. Dose, 3 up to 12 drops. Very severe attack. Was well in three weeks, and grew rapidly very fat. Case 27 -November, 1894 ; female 2 years old. Whooped for ten days. Dose, 3 up to 5 drops. Severe attack. Well in three weeks.

Case 28.-November, 1894 ; male $21 / 2$ years of age. Dose, 2 up to 4 drops. Mild attack. On the fifth day caught cold. Temperature 104 degrees. Dull, stupid, languid. I stopped bromoform and gave aconite and belladonna. In two days resumed bromoform. Now, whooping about once in two days and sleeping and eating well, and coughing much less. Case 29.-Exposed Oct. 22, 1894; boy eight months old. Coughed from the 26th to the 28th quite violently, and on the evening of the 28 th whooped from twenty to thirty times -typically. I gave 2 drops of bromoform at 8 P.M., and at 1 A.M. Temperature normal, pulse 120 . Did not whoop after 11 P.M. until the next day at 7 A.M., two whoops ; $7: 30,2$ drops of bromoform. Temperature and pulse normal. At noon, 3 drops bromoform; at 4 P.M. 2 drops. One whoop at 1 P.M. 6 P.M., temperature 99.4 degrees, pulse 120 , good. Much swallowed mucus in stool to-day. Dull and sick-that night whooped once. Slept well.

October 30. No whooping to-day. Cough loose and very moderate. Gave 5 drops of bromoform during the day. Evening temperature 99.2 degrees, pulse 120 .

October 31, slept well. Bright as usual. Coughed several times-no whoop-ate well. Temperature and pulse normal. November 1. Gave 1 drop of bromoform four times to-day. No whoops.

November 15, an occasional cough. No more whoops.

Shortly after last record, baby caught cold and coughed several times a day. No whoops. Has gained steadily since.

My plan of administration is based on the following idea: begin with a dose which can be well borne, increase as rapidly as is compatible with safety up to the maximum dose, i.e., that dose which distinctly diminishes the number and violence of the whoops. As the number of paroxysms decidedly lessens, and when the patient sleeps all night, I begin to diminish the dose by drops. I give it four times a day as a rule, but in severe cases add an extra dose in the middle of the night. I see the patients frequently, and keep close watch on the condition of lungs, bronchi and heart. I have always exhibited bromoform in its pure state, writing for a given quantity of the drug and ordering it to be put up in a dropping bottle, and to be given in a little water; this I do because it can not be easily dropped in any other way. If you bear in mind the high sp. gr., you will understand why it is difficult to drop, and you will not be surprised to know that there are in the neighborhood of 360 drops in one drachm.

Mr. Geo. W. Hackney, Ph. G., of Pittsburg, has made, at my instance, many experiments looking toward some other and more agreeable method of giving this drug. His work seems to show that emulsions are not palatable; that mixtures are not safe; and that the best way, outside of my own way of giving it in water, is in a mixture of alcohol, glycerin and water.

The first requisite seems unattainable, each mixture or solution seeming to markedly retain the sweet pungent taste of the drug. The second requisite, that of safety, obtains only in absolute solutions-alcohols of various strengths.

I have made it a practice to repeatedly examine the heart and lungs of all cases, and the record has been here omitted only to insure brevity. In no case under observation was there any heart lesion developed, nor was there any moist râles, except in two cases. These cases differed in severity, but Cases 16, 19, 21, 25, 26 were certainly very severe. Case 26 , for example, having, previous to treatment, lost her breakfast eight times in one morning.

Since I wrote the body of this paper, Dr. W. W. nature. obtain. useful.

Johnston, of Washington, has, in the Archives of Pediatrics (April, 1895), called our attention to the great mortality in pertussis. His essay deals with the shadowy side, and we are indebted to him for his exhaustive comparisons and mathematical data. $\mathrm{He}$ deals with things as they are and have been, and not as they may be. I do not want to precipitate a discussion on pertussis as a disease, but only to call to your attention the fact that in the use of bromoform we have a method of controlling this disease and avoiding the great mortality which surely does

There is another class of cases to which I wish briefly to refer, in which bromoform seems to accomplish something unattainable in any other way. I refer to those bronchial subacute colds in adults, in which a very hard, persistent, dry cough obtains, and which seem to resist the drugs ordinarily given for their amelioration. In such cases I have found bromoform to work most effectively; in a very short time reducing the frequency of the cough, causing a moderately free expectoration, and consequently relieving the muscular distress of the patient. To such cases I give the drug in capsule (letting the patient fill the capsule) in doses ranging from 20 to $30 \mathrm{drops}$ every six hours.

The danger signal is usually plainly to be seen; drowsiness following the exhibition of an overdose, usually in course of an hour or two.

In conclusion, let me again lay stress on my method of giving this drug, viz.: begin with a known sate dose, then push to the limit of evident relief of symptoms as rapidly as possible. In this way we may expect to avoid many of the complications and save much time in the treatment of this disease-as well as markedly reduce the mortality.

\section{DOUBLE CLUB FEET AND HANDS - TREAT- MENT.}

Read in the Section on Diseases of Children, at the Forty-sixth Annual Meeting of the American Medical Association, at Baltimore, Md., May 7-10, 1895.

BY B. MERRILL RICKETTS, M.D. CINCINNATI.

The object of presenting this subject and report of a case is to place one of the rarest affections on record, and to draw from its history and treatment any deductions that may be of profit.

It is to be regretted that so little has been accomplished, especially in rendering the club hands more

Unfortunately, the causes do not lie within the domain of surgery - they being manifested in utero.

Whatever the cause may be, the results are practically the same; if it is due to a neurosis, but little can be hoped for in increasing the usefulness of the affected extremity.

If, however, the nerves should not be affected, and the deformity due to an over- or under-developed bone, the greatest benefit usually ensues from some surgical procedure.

There is a condition found in the congenital paral$y$ sis of the extensors of the forearm which does not exist in the congenital paralysis of the extensors of the lower leg, viz., the ankylosis of the elbow joint. This seems invariably the case.

I have not thus far been able to find any report of ankylosis of the knee joint in paralyses of this 